\title{
Language Danger: Metal Gear Solid V and the Weaponization of English
}

\section{Christopher Hall}

University of Kansas, US

DOI: https://doi.org/10.7358/ijtl-2018-003-hall

chris17@ku.edu

ABSTRACT - In the final installment of Hideo Kojima's Metal Gear Solid series, 2015's Metal Gear Solid V: The Phantom Pain, language takes on a function entirely outside of its longstanding role in constructing artistic worlds. Even as it is used to build the world around protagonist Punished "Venom" Snake, spoken language becomes a weapon in the hands of nemesis Skull Face, who deploys a species of deadly parasite that attacks its host's vocal cords, with the eventual aim of destroying the English language and all who speak it. This paper explores both how language is used to construct, in Marie-Laure Ryan's terms, the "storyworld" of MGSV, and how the spoken word comes, through Skull Face, to threaten that world (2014). By applying the rhetorical approach to videogame analysis of Ian Bogost, this project investigates the interpretive potentialities for spoken English as a lingua franca (ELF) made possible by MGSV's "procedural representation" of language, especially regarding English as a weaponizable force ([2007] 2010). In extending Skull Face's implications of English as a destructive power into real-world situations of language-based oppression, the paper shows how MGSV creates opportunities for interrogating the role of the English language in constructing reallife colonial worlds. To contextualize these concerns, the project incorporates other "worlds" that share MGSV's language-based concerns, particularly that of George Orwell's 1984. ELF scholarship, as well as the anti-colonialist work of Paulo Freire and Edward Said, are applied in an exploration of language as a tool for both totalitarianism and revolution, and the article concludes by gesturing toward means of ideological and linguistic decolonization. Through this approach to MGSV, the project conveys the real-world dangers of English as a lingua franca, and theorizes how we might move from media theory to real-world action. 
"Words can kill"

-Skull Face

\section{INTRODUCTION}

Artistic worlds have long been crafted using language of all kinds. Words establish images, smells, feelings, and histories of people and places that may never have been seen by a user or audience. In films and novels, language expresses a character's innermost thoughts and grounds relationships between a story's actors. Even in videogames, where visual elements of graphics and gameplay are often a primary concern, language is essential for establishing rich, experienceable worlds. An especially visceral world of this kind is that constructed by Hideo Kojima in his Metal Gear Solid videogame series and its rich transmedia extensions in comics and novelizations. Kojima's series has frequently emphasized language's role in world-building, particularly the role of English as a spoken language, which is used to convey plot, make connections between various installments, and convey the tortuous, interlocking backstories of the series' characters.

In the 2015 installment in the franchise, Metal Gear Solid V: The Phantom Pain, written and directed by Kojima, spoken language is used to help construct the historical, political and philosophical world within the game. Speech works in this multimodal title to deepen the player's experience as protagonist Punished "Venom" Snake, even as the spoken word becomes a weapon in the hands of Venom's nemesis, Skull Face. Below, I explore first how language - spoken English, as the lingua franca of The Phantom Pain - is used to construct the "storyworld," to use Marie-Laure Ryan's term (2014), of the title, and second, how speech simultaneously comes to threaten that world, calling attention as I do so to the use of spoken language as a weapon in George Orwell's novel 1984 ([1949] 1977). I draw out as well the interpretive potential for interrogating English's role as a real-world lingua franca (or ELF) presented by the game by applying Ian Bogost's concept of "procedural representation" ([2007] 2010). By extending arguments crafted within the game about spoken English, arguments that portray the language as a destructive force associated with colonial militarism, into the example of language-as-weapon in 1984 and into realworld language danger, I show how MGSV creates opportunities for interrogating the role of English at large as a tool for constructing the real-life worlds of colonialism and imperialism. Finally, I explore how spoken language might also function as a tool for rebellion and decolonization, 
whereby peoples living within the oppression of colonial worlds can begin to push back through collaborative speech and move to reestablish the worlds that have been displaced by colonial imposition.

\section{NARRATOLOGY AND RHETORIC IN METAL GEAR SOLID V}

Released in September 2015 after prologue Metal Gear Solid V: Ground Zeroes the year prior, The Phantom Pain is an open-world stealth and espionage game. The title was critically acclaimed and commercially successful, and it marks the final game Kojima published through Konami before the two parted ways after its release. The sprawling action of The Phantom Pain takes place mainly in Afghanistan and Southern Africa in 1984, as the player guides Venom through 50 story missions gathering intelligence, sabotaging enemy bases, and attempting to get closer to Skull Face in order to exact revenge for his destruction of Venom's Mother Base at the close of Ground Zeroes. In the interim, the player also accumulates resources and recruits personnel in an effort to rebuild Mother Base and strengthen Venom's private army, Diamond Dogs. Even after Skull Face is defeated, along with his nuclear-armed walking tank, Metal Gear Sahelanthropus, Venom must confront a deadly strain of vocal cord parasites engineered by Skull Face. These parasites, with their capacity to eradicate entire languages and peoples, form the central impetus for the weaponization I point to in my title, and ground The Phantom Pain's rhetorical arguments about language.

\subsection{Storyworlds and Language}

To establish the makeup of the world of Kojima's game, a makeup which holds as well in the cases of other worlds examined below, I look to MarieLaure Ryan and Jan-Noël Thon's 2014 co-edited volume Storyworlds across Media: Toward a Media-Conscious Narratology. In her essay "Story/ Worlds/Media: Tuning the Instruments of a Media-Conscious Narratology," Ryan makes a vital distinction, while discussing the "worlds" of various kinds of media, between the general ways that media-based worlds are understood colloquially, and what she specifically terms "storyworlds." Unlike the "worldviews" presented in media by their creators, or the "world of the author" that extends beyond a story into the real world, a 
storyworld is "something projected by individual texts" that "requires narrative content" (Ryan 2014, 32). In this formulation, "every story has its own storyworld" (ibid.). The storyworld concept provides a rigorous basis for exploring the ways that experiences of media are narratologically composed, embracing questions of the roles various elements play in artistic construction, how the user comprehends these elements and the construction at large, and why these particular elements might have been selected. Ryan and Thon's concept of storyworlds also establishes an important narratological grounding for the phenomenon of transmedia storytelling, where stories travel between different media and storyworlds.

Ryan and Thon, in their introduction to Storyworlds across Media, aim at "expand[ing] the scope of narratology beyond its 'native' territory of language-based narrative" $(2014,2)$, noting that language is a fundamental medium of storytelling. The broad role of language in storytelling, of course, presents certain difficulties in using language as a point of entry into a discussion of storyworlds. Ryan cautions that "The concept of storyworld represents a departure from the idea ... that the experience of literature ... is essentially an experience of language" $(2014,43)$. This need not imply that the role of language be ignored however, but rather that language should not be taken as the sole proprietor of experience in a text. In the discussion that follows I investigate the role of language, not as the lone dictating element in various kinds of worlds, but as one aspect of many that participates in their construction, an aspect that, in its very function in the texts I cover, calls into question the power it wields.

\subsection{Mounting Arguments across Worlds}

To tackle theoretical concerns of language directly, I also apply here the videogame-centered theory of Ian Bogost. Bogost, in Persuasive Games: The Expressive Power of Videogames, approaches videogames from the perspective of their "Procedural rhetoric ... a technique for making arguments with computational systems and for unpacking computational arguments" $(2010,3)$. This approach allows for the isolation of a theme in videogames, in this case spoken English, and prompts questions about it, such as: what arguments about English are mounted, what claims are made, and what further opportunities for interrogating the role of this theme are presented? Just as "we can interrogate literature, art, film, and daily life for the under- 
lying processes they trace," Bogost contends that we can do the same with videogames $(2010,5)$. As the player moves procedurally through a game by taking actions, accomplishing tasks, responding to prompts, and generally becoming more literate in the machinery of the game's world, the game reveals rhetorical positions on its major concerns. From this it is possible to draw conclusions about the persuasive content of a game, precisely as I do below for The Phantom Pain.

Bogost's approach, as evidenced by his desire to bring videogames into conversation with "literature, art, [and] film," is a natural partner for Ryan's storyworld theory. Ryan provides a large-scale structure for mediabased investigation, one that considers connections between various kinds of media. Bogost, in turn, offers a scaffolding for tackling specific issues and arguments within videogames. Together, they allow for a theoretical transition from concerns of world-building and procedurality within media, to claims and arguments regarding the real world. In Persuasive Games, Bogost invites consideration of how arguments mounted procedurally within games can prompt responses in the player's life, while Ryan initiates an examination of how various worlds relate to one-another. Here the two theorists come together in a way that allows for a move from The Phantom Pain's storyworld into the real world.

What emerges are overlapping worlds with ties to both the storyworld of The Phantom Pain and the real world. One such world procedurally posited by the game is the militaristically constructed colonial or imperial world. Whereas a storyworld is "something projected by individual texts," a colonial or imperial world might be understood as being projected by an oppressor (Ryan 2014, 32). These worlds, as Skull Face's childhood oppression in World War II era Hungary testifies through the game's colonial rhetoric, are projected through the oppressor's spoken and written language ${ }^{1}$. Edward Said, in his classic text Orientalism ([1978] 1994), notes how as part of Napoleon's imperialist move into Egypt, "the Orient was reconstructed, reassembled, crafted, in short, born out of the Orientalists' efforts," that "After Napoleon ... the very language of Orientalism changed radically. Its descriptive realism was upgraded and became not merely a style of representation but a language, indeed a means of creation" (2014, 87).

${ }^{1}$ Colonial worlds, and their relationship to the rhetoric of The Phantom Pain (and Skull Face's backstory), are further explored in sections 4 and 5 . 
Napoleon, through the efforts of his scholars, endowed Orientalist rhetoric with the power to redefine Egypt's cultural world in the eyes of the West, effectively overwriting its pre-colonized being. In this way, he created a new Orientalist political world in Egypt itself and in scholarship concerning the country, worlds assembled through the assimilative power of force. Imperialist authority, viewed through the lens of world-based theory, takes on an aspect of authorship as its military and scholarly assemblages construct and dictate a story about what the colonial environment is and what is possible within it. That is, there is a narrative content to imperialism that is also a political content.

\section{BUILDING AND EXPERIENCING SPEECH-BASED WORLDS}

The multimodal storyworld of The Phantom Pain is constructed through the coordination of speech, visual/graphical elements, characters, gameplay mechanics, and more. The title draws upon the power of the spoken word to convey plot and establish a mythology, as do many games, using cutscenes and dialogue to help construct an aesthetic and politics that define the user's experience of its world. Kojima has consistently made a point of emphasizing the importance of spoken language throughout the Metal Gear Solid series; speech is a key source for the player's experience of Kojima's storyworlds and an essential means for the cooperative world-construction that takes place between game and player. The mass of spoken explication in virtually every Metal Gear Solid entry, alongside plot- and gameplaybased concerns with speech-centered interactions, gives the titles an oralliterary quality. This focus on language at large is not unique within videogames - role-playing games and text-based titles have long leaned on the written and spoken word for the construction of their worlds. Works in the stealth and espionage genre, however, typically privilege silence, making the fascination with oral language in the Metal Gear Solid franchise distinctive ${ }^{2}$. As Ryan states, a storyworld "is a dynamic model of evolving situations, and its representation in the recipient's mind is a simulation of the

2 The Phantom Pain explores this tension between genre and storyworld through characters like sniper Quiet, who is unable to speak because of a vocal cord parasite infection and consequently remains an opaque presence in the narrative. While her condition is conducive to her occupation, it keeps her at a remove from the player.

International Journal of Transmedia Literacy - 4 - December 2018

http: //www.ledonline.it/transmedialiteracy - Online ISSN 2465-2261 - Print ISSN 2465-227X 
changes that are caused by the events of the plot" (Ryan 2014, 33). The plot of The Phantom Pain, and of the series at large, is conveyed using speech to such an extent that entries have become notorious for their incredibly long and dialogue-heavy cutscenes. Tanner Higgin, writing about Metal Gear Solid 2: Sons of Liberty (2001), cites game designer Patrick Redding, who notes Sons of Liberty's "extremely disruptive in-game dialogues ... that dragged on and on" $(2010,253)$. The greatest offender in this respect in the series is often held to be Metal Gear Solid 4: Guns of the Patriots (2008), which, as IGN reviewer Jeff Haynes noted at the time of its release, contains one cutscene alone that clocks in at around 45 minutes in length. Even these drawn-out cinematic additions are an improvement on the "codec" conversations of earlier Metal Gear entries, wherein two characters appear from the neck up, reciting lines of dialogue that appear in the center of the screen. While Redding calls such dialogues "disruptive," it is important to note that they are disruptive - and variably so - only of the interactive gameplay, not of the player's experience of the storyworld, which to the contrary is enriched through these lengthy digressions from gameplay.

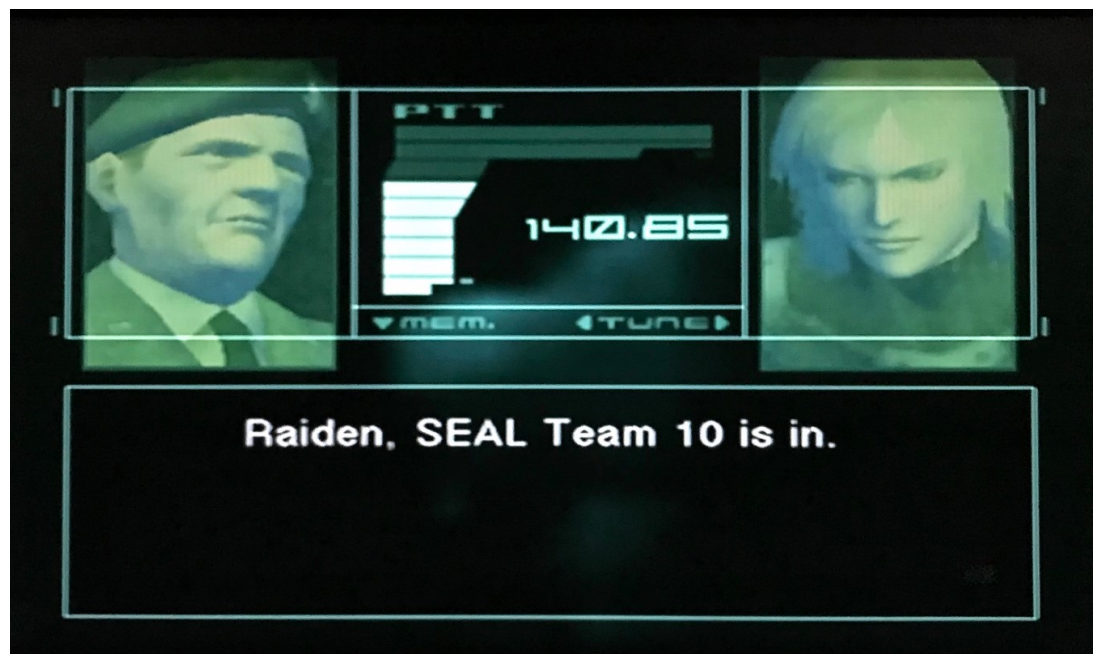

Figure 1. A codec conversation from Metal Gear Solid 2.

Beyond the flood of speech that fills entries in the series, there are complications explored in recent titles. While Guns of the Patriots contains an 
almost laughable amount of dialogue, the game, and Kojima, are clearly aware of this overload. Some cutscenes in the title feature an excess of superfluous camera options, calling attention to the overbearing absurdity of Kojima's movies-within-the-game but also emphasizing the importance of the cutscene's spoken content to the storyworld. That is, whatever it takes to entertain or amuse the player as the discussion takes place, it is essential that we participate in this speech-based world-structuring and interpolate its information into our understanding of the game's world ${ }^{3}$. Although the codec conversations have now been stripped from the series, and the cutscenes are considerably shortened in The Phantom Pain compared with some of its predecessors, this most recent title is still brimming with oral language, especially in its taped recordings, which include everything from 80's music to conversations revealing key backstory. From the perspective of Bogost's theory, the verbal content of the title mounts a procedural argument about spoken language, insisting on its relevancy to the player's comprehension of The Phantom Pain's world ${ }^{4}$.

Receiving and responding to speech is one of the crucial ways in which the user comes to comprehend the worlds of Kojima's series and establish a literacy within them. The user who engages with a large portion of the available language-based content of The Phantom Pain experiences an accrual of intra-world texture that provides depth and breadth, increasingly involving them in the game's plot and dynamically mediating their understanding of it as they move through the procedural domain. The more the player engages with the oral information available, the more the game's storyworld teaches the player about itself, and about their (and Venom's) place in it. As Constance Steinkuehler has written with regard to literacy and games, "video games are about a back and forth between reading the game's meanings and writing back into them" (2010, 61). The player's competency for participating in this game-player exchange increases with their comprehension of the game's storyworld. In this way, their literacy within the game world increases, and they have a greater sense of how their actions within the game affect the storyworld. Oral English, as a key vehicle

${ }^{3}$ Earlier entries in the series provide more rudimentary examples of cutscene interactivity. In Metal Gear Solid 2: Substance (2003), for example, the player can pan and zoom the camera during some cutscenes, and can press a button during codec conversations to elicit angry or sarcastic replies from protagonist Raiden.

${ }^{4}$ While one could play through the game without watching the cutscenes or listening to the tapes, this user's experience would be very superficial given the content available. 
for The Phantom Pain's expression of its world, takes on a great deal of value in this back and forth, an exchange that is increasingly threatened as the game progresses.

\section{RHETORIC AND WEAPONIZED LANGUAGE}

To contextualize the procedural aspects of The Phantom Pain's arguments about language, I turn first to a parallel example. In Persuasive Games, Bogost discusses the procedural claims mounted within the popular 2004 title Grand Theft Auto: San Andreas. In the game, Bogost notes, the player is required to feed their character, "However, the only nourishment in the game comes from fast food restaurants" $(2010,113)$. Among other claims, Bogost argues that the procedural representation of the food economy in San Andreas "serves to expose the social forces that drive the poor and working-class residents of the inner city to consume fast food habitually" (2010, 115). The lack of healthy food options for the game's inhabitants calls attention to real-world obstacles for inner-city residents who would attempt to follow a healthy diet. San Andreas does not explicitly state that the urban poor of America lack the necessary access to healthier food options, but the user's procedural experience of this dearth of choices can lead to the player asking why this is the case, and to questioning whether these circumstances reflect those of the real world.

The Phantom Pain similarly mounts procedural claims about speech, especially through the player's interactions with Skull Face. In the penultimate mission of the first part of The Phantom Pain, the Hungarian Skull Face delivers a harrowing monologue about the role of English in his life: "I was born in a small village; I was still a child when we were raided by soldiers ... I was made to speak their language.” The young Skull Face was stripped of his Hungarian mother tongue and forced to speak other languages, including English. The experience filled him with a hatred of English and its growing role as a lingua franca, and his views and history rhetorically posit the language as a destructive and oppressive force wiping out other languages as it becomes increasingly ubiquitous, a force closely bound up with imperialism.

The destructive potential of speech emerges in varying forms in literary storyworlds as well. In George Orwell's 1984, for example, set in the 
same year as MGSV, language at large acts as a weapon of political oppression. As part of the efforts of Big Brother to repress free speech and the fermentation of rebellion, the government within the novel has instituted the official language of Newspeak. The rhetoric of this imposition of language by force within the totalitarian state of the novel's storyworld pairs closely with The Phantom Pain's procedural rhetoric about speech, as Orwell also mounts a cautionary argument about militarized attacks on the spoken word. Like Skull Face, characters in 1984 experience the frustration and restriction of being coerced into speaking only within an acceptable norm. In both cases, the toll taken by this imposition encourages consideration of real-world parallels, although the works approach speech-based danger and oppression from different perspectives.

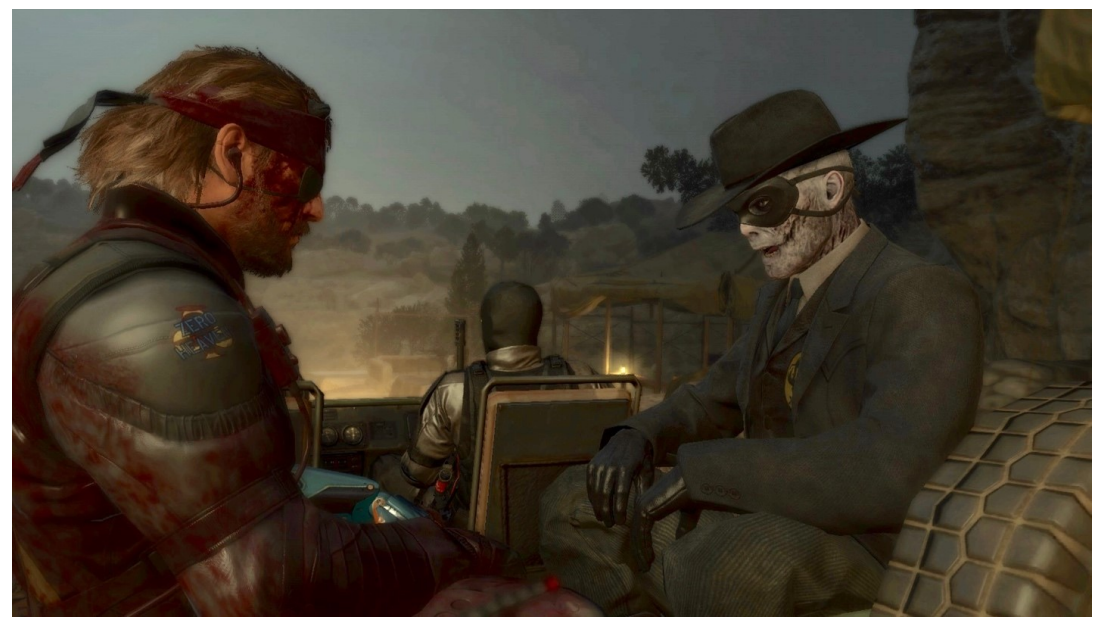

Figure 2. Skull Face delivering his monologue in Metal Gear Solid V.

"Words can kill," Skull Face asserts in his monologue. Within The Phantom Pain's storyworld, he means this quite literally. Over the course of the game to this point, Skull Face has researched and deployed a species of deadly parasite that attacks the host through their vocal cords, reacting only when a specific language is spoken. With the assistance of these parasites, Skull Face has endeavored to wipe out the speakers of various languages within the game. His combat uses of these parasites begin on a relatively small 
scale - Russian and Pashto strains specifically targeting Soviet and Hamid combatants in Afghanistan, Afrikaner and Kikongo strains targeting private forces in Africa - but by the time the player reaches the mission in question it has become clear that Skull Face is also developing a strain engineered to destroy English as an oral language, killing any who would speak it ${ }^{5}$. It is stopping this erasure which occupies the latter portions of the game's story. "Sans lingua franca," Skull Face tells Venom, "the world will be torn asunder. And then it shall be free." Having been presented with Skull Face's experience of oral English, the player is procedurally urged to consider the connection between language and (imperial) violence. Skull Face's childhood in particular - oppressed by foreign invaders seeking to impose their ways of being on him and his fellow citizens - suggests resonances in the oppressed worlds of colonialism.

\subsection{Skull Face and Threats to Worlds}

Skull Face mounts a rebellion against a generalization of the imperial powers that oppressed him as a child, seeking to become oppressor to the oppressors and to subvert a hegemony of spoken language. "I was invaded by language," Skull Face asserts during the abovementioned monologue. Having experienced firsthand the potency of language as an oppressive tool capable of altering identities and restricting conceptualization, Skull Face attempts an invasion of his own, using the parasites to weaponize speech.

This results in some particularly affecting fallout in the game, especially when the player must enter the quarantine platform of Venom's Mother Base and eliminate a number of Snake's fellow soldiers who have become infected. Speech here becomes a weapon procedurally allocated the power within the storyworld to destroy that world. Venom's ally Code Talker describes the potential devastation during this mission, relating how the parasites trigger "an overwhelming urge to get out in the open ... Once outside, the birds will feed on the infected bodies, spreading the parasite on

${ }^{5}$ The game is notably silent on the issue of written language. Presumably the vocal cord parasites would be unresponsive to nonverbal uses of the target language. This single-minded preoccupation with verbal communication only further engrains the oral nature of Kojima's title. 
land. The whole world will be infested!" ${ }^{6}$ The Phantom Pain mounts a procedural argument here that language can be a world-defining tool and a world-destroying weapon. The player's experience of this portion of the game is couched in the actuality of the procedural threat of the parasites to the storyworld, as it is the potency of this threat that is used to justify the murderous actions of the player on the quarantine platform.

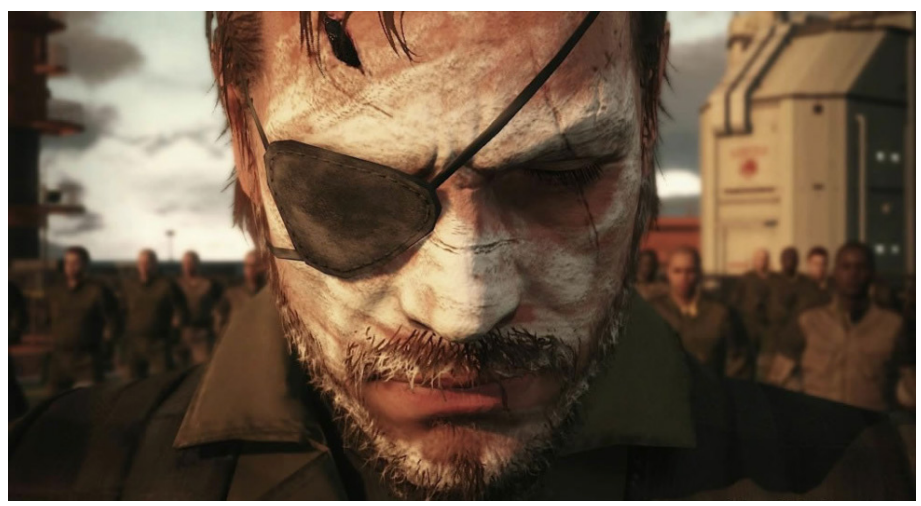

Figure 3. Venom, following the mission on the quarantine platform.

\subsection{4 and the Transworld Weaponization of Language}

1984 also mounts a rhetorical case that language, in speech and thought, is a key tool for oppression. Although Newspeak is not yet in the novel's present the dominant means of communication - the lingua franca - for Oceania, rules regulating speech and thought are already in place, increasing the oppression of Airstrip One citizens by restricting their possibilities for imagination and freedom of expression. As Syme, an individual working on the Newspeak dictionary puts it, "the whole aim of Newspeak is to narrow the range of thought" (Orwell, 1977a, 52). The eventual intention of the Big Brother government is for citizens of Oceania to be simply unable

${ }^{6}$ More accurately, this is a threat to only the English-speaking world of the game, but given the storyworld's rhetorical privileging of English, Code Talker's generalization is understandable.

International Journal of Transmedia Literacy - 4 - December 2018

http: //www.ledonline.it/transmedialiteracy - Online ISSN 2465-2261 - Print ISSN 2465-227X 
to speak their mother tongue, in this case colloquial English, or Oldspeak. "The purpose of Newspeak was not only to provide a medium of expression for the world-view and mental habits proper to the devotees of Ingsoc, but to make all other modes of thought impossible," Orwell writes in the "Principles of Newspeak" essay appended to the novel (1977b, 298-9). In this way, the Big Brother government aims to make Oceania's citizens simply unable to speak their native language, much like the characters in The Phantom Pain who have become infected by the vocal cord parasites.

However, in the interim stage of Newspeak's development during which the novel takes place, wherein the meanings and words of Oldspeak have not yet been eradicated, speech itself can be an act of rebellion. During one of protagonist Winston Smith's trysts with lover Julia, Smith makes note of

the coarseness of her language. Party members were supposed not to swear ... Julia, however, seemed unable to mention the Party ... without using the kind of words that you saw chalked up in dripping alleyways ... It was merely one symptom of her revolt against the Party. (Orwell 1977a, 122)

This sort of political resistance is largely personal, and not a realistic way of effecting change, but within the storyworld of 1984 it marks a vital distinction between a state where rebellion is trivial and difficult to carry out without retribution, and the future enforcement of Newspeak, when such linguistic rebellion will become literally impossible and the tools for it will no longer exist. Orwell's storyworld rhetorically invites the reader here to question tendencies toward tyranny in current governments and the methods available for overturning them, should organized revolt cease to be possible. It also invites consideration of whether any escape would be feasible, were an oppressor to attain control over the speech and thought we use to describe and understand our reality and our lived world.

As Winston ponders during his later captivity in the Ministry of Love, empirical facts, like "The so-called laws of nature," depend upon there being "a 'real' world where 'real' things happened. But how could there be such a world?" (1977a, 278). 1984 prompts consideration of the transworld power of words, both to oppress and to combat oppression, a power that, as Juan Francisco Fuentes has pointed out, has historically been a central instrument in oppressive measures carried out by real-world totalitarian regimes. Beyond the basic language-based oppression and conceptual 
limitation attempted through propaganda, Fuentes notes totalitarianism's attempts to eradicate

the political language of liberalism without instead creating a new language. Its failure is more evident if we consider the slang for internal use developed by totalitarian regimes, so as to produce the illusion of a real language able to overcome the world and the words associated with liberalism. $(2013,53)$

What these regimes end up with, Fuentes notes with a nod to Orwell, is a Newspeak of their own - euphemisms, slogans, and neologisms intended "to obliterate the world of ideas, values, institutions, concepts, and words set up by liberalism" $(2013,52)$. The hollow concepts remaining are geared toward instilling precisely the ontological and epistemological uncertainty that Winston experiences, via a kind of lingual and political solipsism. 1984 argues that the creeping oppression of totalitarianism must be fought with words, before it becomes too late.

\section{A REAL-WORLD TURN}

The fictional worlds of The Phantom Pain and 1984, shaped by their applications of and arguments about (spoken) language, are ones where characters are linguistically oppressed, and these arguments present real-world implications. Bogost invites this kind of leap, as the arguments mounted within the storyworlds of games construct positions directly concerned with the lived worlds outside of them, like those of colonialism, imperialism, and totalitarianism. For Ryan, such a move takes us out of the storyworld and into a potential worldview presented by the game, but the shift can be a fruitful one. We are encouraged by The Phantom Pain's procedural representation of the oppressed who wants to become an oppressor (Skull Face), and the role speech plays in his oppression, to interrogate the part of oral English in constructing real-life worlds.

\subsection{Language Danger and ELF}

In a recovered tape in Ground Zeroes, Skull Face mourns that World War II imperialism destroyed "the last identity I had left - the words I spoke." 
Skull Face was displaced from his native culture and language in the chaos of World War II, his Hungarian homeland caught between Hitler's Germany and Stalin's Soviet Union. Of course, imperialism and colonialism, closely intertwined political projects, have ravaged world communities long before and since the middle of the $20^{\text {th }}$ century. As Andrew Dalby argues in his 2002 book Language in Danger, Skull Face's hated lingua franca has been guilty of not only being a tool for ideological supplanting and forced assimilation, but of actually annihilating entire languages en masse: "While the use of English spreads all around us we are also seeing ... the rapid disappearance of hundreds, eventually thousands, of minority languages" $(2002,207)$. This is not to contend that the growth of English is in every case the cause for the extinction of other languages, but rather to interrogate this relationship. In the context of The Phantom Pain's procedural argument, I therefore mean the concept of language danger, or "language in danger," to refer not only to the weaponization of language within a storyworld but also to the real-world destruction of indigenous languages, and to question whether spoken English presents a trans-world danger to other languages.

There are a number of counter arguments to Dalby's macro-level view of ELF as a global force of linguistic displacement. Juliane House has made a case for the utility of English as "a transactional language," a common ground for making connections and conducting business across barriers of language and culture $(2003,560)$. She argues that "Using ELF for instrumental purposes does not necessarily displace national or local languages, as they are used for different purposes" (ibid.). Similarly, Anna Mauranen, in English as a Lingua Franca: Studies and Findings, has focused on English "as a vehicle of efficiency in for example business and science, or as a new means of communication for globally emergent localities in a variety of nonmainstream subcultures" $(2009,1)$. In drawing on a body of work that embraces this premise, Mauranen's collection explores the machinery of ELF through case studies such as Martin Dewey's "English as a Lingua Franca: Heightened Variability and Theoretical Implications." Like House, Dewey makes connections between the growth of spoken English as an inclusive international language for business, while also questioning its use as a means of exclusion via immigration tests and the restrictive norms - the "exercise in error spotting" - that such tests often boil down to $(2009,71)$.

Arguments from ELF like these are often couched in assumptions of the general benefit to be had from expanding a community of speakers. 
Despite the lag that Dewey points to between ELF scholars embracing English as a fluid, inclusive force, and the standards of government testing, his position builds on House's, especially where the latter underlines the advantages of English as a hybrid language. House, with reference to Mikhail Bakhtin's work on dialogue and multi-voiced narrative, argues for a new method for "conceptualising and researching ELF ... 'a third way', which steers clear of the extremes of fighting the spread of English for its linguistic imperialism, and accepting it in toto for its benefits" $(2003,574)$. As Bakhtin has outlined in "Discourse in the Novel" ([1973] 1981), there are both centripetal and centrifugal forces within language, or ways in which language is constantly being both unified and dispersed through usage: "Every utterance participates in the 'unitary language' (in its centripetal forces and tendencies) and at the same time partakes of social and historical heteroglossia (the centrifugal, stratifying forces)" (1981, 272). As he explores the plurality of voices that make up novels and language, Bakhtin emphasizes their constant fluctuation and living quality.

House, via Bakhtin, rightly makes the case that neither blanket statements about English as a positive or negative force should be accepted unquestioningly, and that a language in use is never static and monolithic. However, in circumstances where a particular language's use is militarily imposed or is strongly privileged, as is typically the case in colonized lands, the sort of open-ended and cooperative growth Bakhtin envisions is curtailed, as the language is directed centripetally even as its body of users grows. This sort of linguistic shaping by force, through top-down attempts to adhere to arbitrary standards of use, continues, as Dewey points out, in immigration centers in the West. We see it as well in 1984 and in Skull Face's use of the parasites. His attempt to eradicate English is an extreme case from an opposite position - the total and intentional wiping out of the linguistic standard of the minority world. While spoken English in the abstract is not an essentially imperialistic force, the utopianism of House's view that the more English spreads, the better off everyone is, bears a second look considering how this spread has been enacted and its dynamics of power and violence. The Phantom Pain provides a procedural space for contemplating this. 


\subsection{Countering Oppression through Language}

In the storyworld of The Phantom Pain, speaking English can threaten the collapse of this world and represents the in-game manifestation of a linguistic totalitarianism aimed at both limiting the range of thought and actually destroying whole languages. 1984's storyworld and its rhetoric similarly direct readers to reflect on militant political applications of speech and its potential to circumscribe lived worlds. Likewise, the language of the colonizer, as a means of displacing the language of the colonized, threatens the world of the colonized in ways that are not solely linguistic. The methods of communication available to a colonized people, their foundational concepts, their means of education, are all grounded in the spoken language that structures and perpetuates their culture, and this is threatened when there is imposition of an external language bearing its own attendant ideologies.

Within the real-world oppression of colonialism and the languagebased imperialism that constructs its worlds, making lasting impacts on native languages or displacing them entirely, there are opportunities for speech-based rebellion. As in 1984, language and the act of speaking can take the form of revolt, and not only in a symbolic sense. Paolo Freire, in Pedagogy of the Oppressed, contends that in an oppressed society, "Organizing the people is the process in which the revolutionary leaders ... initiate the experience of learning how to name the world ... the leaders cannot say their word alone; they must say it with the people" ([1968] 2000, 177-8). For an oppressed people to retake their world there must be an inclusive practice of dialogue; in this way, by talking - by naming - a group can begin to rebuff their oppressors and reclaim their world. Through this political and pedagogical process, the people of a colonial world, one projected upon them by the colonizer, can rhetorically project a new collaborative world of their own or reassert an old one. In this way, the people reclaim authorship of their lived world. As Freire phrases it, "revolutionary leaders must follow the path of dialogue and of communication" (2000, 162). A revolution of this kind must come from within a community, and it must involve the voice of the native population in a taking-back of the linguistic "means of creation," as Said puts it $(1994,87)$.

Freire's project, read through The Phantom Pain via the real-world turn encouraged by Bogost, directs us toward the necessity for ideological and linguistic decolonization. Walter Mignolo has described decolonization 
as a "task [that] consists in unveiling beliefs and assumptions, anchored in common sense" $(2011,26)$. This is not a matter of substituting a new hegemony for the old one. Chinua Achebe, exploring the tension between the utility of written and spoken English and the need to continue working in his native language, looked to find a community for his writing in a way that avoided thinking of the issue as a binary:

On language we are given ... simplistic prescriptions. Abolish the use of English! But after its abolition we remain seriously divided on what to put in its place ... I can see no situation in which I will be presented with a Draconic choice between ... English and Igbo. For me, no either/or; I insist on both. $(1990,60-61)$

Achebe's take here has some commonality with House's "third way," embracing the utility of English while resisting its potential to displace his native language. There is a path forward in dialogic practice, but it must not be coercive.

Language in Freire and Achebe emerges as a communal pedagogical tool, one that can be put to use to subvert the very forces that instituted it. Where Skull Face would attempt a rebellion of revenge in a bid at eradicating the language of his oppressors, Freire provides a way for the oppressed to use their spoken language to resist that oppression and rebuild their worlds through decolonization. By crafting and sharing a narrative about their world, colonized peoples can also craft their lived world itself. It is to formulations like Freire's and Achebe's, formulations that emphasize the need for speech and communication while not ignoring potentially oppressive dangers, that Skull Face and The Phantom Pain's procedural representation of spoken language have the capacity to direct the player, opening possibilities for language not as a weapon of destruction and oppression, but as a resource for positive communal change and the recovery of lived worlds.

\section{CONCLUSIONS}

In the foregoing pages, I have attempted to explore the English language, especially in its spoken form, as a weaponizable force, one that is not in and of itself essentially oppressive or liberatory, but that rather is available for 
appropriation toward these ends. Metal Gear Solid $V$ presents a singular opportunity for directly engaging with this weaponization because of the visceral way it ties together speech and violence through Skull Face and his vocal cord parasites, involving the player as it does so in a procedural process that problematizes English's role as a lingua franca. Ryan and Thon's theory is essential here for the narratological stabilization it contributes with its concept of storyworlds, and their theory will continue to be integral to projects like this one which attempt to draw out the rich argumentative potential of multimodal texts.

It is important to note that the arguments to be found in popular texts like videogames are not merely occasions for rhetorical exercises, but that they mount sophisticated and significant positions regarding the world outside of their fictions. In moving between the real world we encounter in day-to-day life, and the environments we explore when becoming immersed in storyworlds, we find that our perspectives on the former are modified by our experiences with the latter, that the densely textured worlds of works like The Phantom Pain have the power to reveal to us latent mechanisms of our reality. It is with this in mind that the preceding has attempted to make apparent the very real oppressive means to which English is often put, rendered discernable by the arguments of Kojima's game and Orwell's novel. The positions mounted in these works act as important counters to minority world conceptualizations of ELF as an objective good and to the sort of imperialist applications of language Said describes. In dramatizing this oppression within their storyworlds, The Phantom Pain and 1984 posit the possibility of language-related coercion and violence as a real-world problem, and therefore also steer the user to projects, like Freire's, that present a way to push back.

Clearly issues of language danger, transmedial storyworlds, and decolonization are incredibly nuanced, and regrettably this article has been able to engage only cursorily with a few of the implications to be drawn from bringing these concerns together. As the field of transmedia studies continues to grow, scholars will discover new ways in which the unique worlds of the texts we use can impact our understanding of the world(s) around us. This work is especially to be desired where it reveals the machinery of oppression, and provides ways of countering it. The push for decolonization within postcolonial studies is an indispensable method for this, and there is much more work to be done in engaging with transmedial texts in terms of imperialism, colonialism, and oppression; such future 
endeavors, it is to be hoped, will point the way to further means of communal resistance and revolution. In continuing to advance the sort of transworld technique attempted here, transmedia studies can make a push for polyvocal critical spaces that reveal the workings of our worlds, both textual and social.

\section{REFERENCES}

Achebe, Chinua. 1990. "The Writer and His Community". In Hopes and Impediments: Selected Essays, 47-61. New York: Anchor Books.

Bakhtin, Mikhail. (1973) 1981. "Discourse in the Novel". In The Dialogic Imagination: Four Essays, 259-422. Austin, Texas: University of Texas Press.

Bogost, Ian. (2007) 2010. Persuasive Games: The Expressive Power of Videogames. Cambridge, Massachusetts: MIT Press.

Dalby, Andrew. 2002. Language in Danger. New York: Penguin Press.

Dewey, Martin. 2009. "English as a Lingua Franca: Heightened Variability and Theoretical Implications”. In English as a Lingua Franca: Studies and Findings, edited by Anna Mauranen and Elina Ranta, 60-83. Newcastle: Cambridge Scholars Publishing.

Freire, Paulo. (1968) 2000. Pedagogy of the Oppressed. New York: Continuum.

Fuentes, Juan Francisco. 2013. "Totalitarian Language: Creating Symbols to Destroy Words". Contributions to the History of Concepts 8 (2): 45-66.

Haynes, Jeff. 2008. "Metal Gear Solid 4: Guns of the Patriots Review". IGN. Last modified June 12. http://www.ign.com/articles/2008/06/12/metal-gearsolid-4-guns-of-the-patriots-review.

Higgin, Tanner. 2010. “'Turn the Game Console off Right Now!': War, Subjectivity, and Control in Metal Gear Solid 2". In Joystick Soldiers: The Politics of Play in Military Video Games, edited by Nina B. Huntemann and Matthew Thomas Payne, 252-271. New York: Routledge.

House, Juliane. 2003. "English as a Lingua Franca: A Threat to Multilingualism?" Journal of Sociolinguistics 7 (4): 556-578.

Mauranen, Anna. 2009. Introduction to English as a Lingua Franca: Studies and Findings, edited by Anna Mauranen and Elina Ranta, 1-7. Newcastle: Cambridge Scholars Publishing.

Mignolo, Walter. 2011. "Decolonizing Western Epistemology / Building Decolonial Epistemologies". In Decolonizing Epistemologies: Latinalo Theology and Phi- 
losophy, edited by Ada María Isasi-Díaz and Eduardo Mendieta, 19-43. New York: Fordham University Press.

Orwell, George. (1949) 1977a. 1984. New York: Signet Classic.

Orwell, George. (1949) 1977b. "The Principles of Newspeak”. In 1984, 298-312. New York: Signet Classic.

Ryan, Marie-Laure, and Jan-Noël Thon. 2014. Introduction to Storyworlds across Media: Toward a Media-Conscious Narratology, edited by Marie-Laure Ryan and Jan-Noël Thon, 1-21. Lincoln: University of Nebraska Press.

Ryan, Marie-Laure. 2014. "Story/Worlds/Media: Tuning the Instruments of a Media-Conscious Narratology". In Storyworlds across Media: Toward a Media-Conscious Narratology, edited by Marie-Laure Ryan and Jan-Noël Thon, 25-49. Lincoln: University of Nebraska Press.

Said, Edward W. (1978) 1994. Orientalism. New York: Vintage Books.

Steinkuehler, Constance. 2010. "Video Games and Digital Literacies". Journal of Adolescent \& Adult Literacy 54 (1): 61-63.

\section{Audio Visual MEDiA}

Grand Theft Auto: San Andreas. 2004. New York: Rockstar Games. Videogame.

Metal Gear Solid V: Ground Zeroes. 2014. Directed by Hideo Kojima. Tokyo: Konami. Videogame.

Metal Gear Solid V: The Phantom Pain. 2015. Directed by Hideo Kojima. Tokyo: Konami. Videogame.

Metal Gear Solid 2: Sons of Liberty. 2001. Directed by Hideo Kojima. Tokyo: Konami. Videogame.

Metal Gear Solid 2: Substance. 2003. Directed by Hideo Kojima. Tokyo: Konami. Videogame.

Metal Gear Solid 4: Guns of the Patriots. 2008. Directed by Hideo Kojima. Tokyo: Konami. Videogame. 